\title{
ТЕХНОЛОГИИ ИСКУССТВЕННОГО ИНТЕЛЛЕКТА В ОБРАЗОВАНИИ
}

\section{Пьрнова О.A., Зарипова Р.С.}

Казанский государственный энергетический университет,

г. Казань, Российская Федерация

Данная статья посвящена применению искусственного интеллекта в образовательной среде. Рассматриваются новейшие технологии, которые уже играют огромную роль как для преподавателей, так и для обучающихся. Также, затрагивается тема будущего искусственного интеллекта в образовании.

Ключевые слова: информационные технологии; искусственный интеллект; образование; информация.

\section{TECHNOLOGIES \\ OF ARTIFICIAL INTELLIGENCE IN EDUCATION}

\section{Pyrnova O.A., Zaripova R.S.}

Kazan state power university, Kazan, Russian Federation

This article focuses on the use of artificial intelligence in the educational environment. We consider the latest technology, which already play a huge role for both teachers and students. Also, the topic of the future of artificial intelligence in education is addressed.

Keywords: information technology; artificial intelligence; education.

В настоящее время существует много программ искусственного интеллект (ИИ), помогающие в образовании, благодаря которым студенты, школьники и учителя получают огромную пользу. Огромным преимуществом является то, что образовательная платформа 
адаптируется в соответствии с потребностями студентов. Система разработки программного обеспечения ИИ помогает ученым работать над своими слабостями. В ходе процесса программа обнаруживает, где у ученика возникают трудности, и отправляет необходимые материалы для улучшения навыков. Адаптивное обучение использует базовый алгоритм искусственного интеллекта. Кроме того, образование в любое удобное время несомненно является огромным плюсом для обучающегося. Сейчас уже известны такие программы, основанные на ИИ. Рассмотрим их.

Автоматическая оценка. Специализированная компьютерная программа, основанная на искусственном интеллекте, которая имитирует поведение учителя, проставляющего оценки за эссе, написанные в образовательной среде. Она может оценивать знания студентов, анализировать их ответы, давать обратную связь и составлять индивидуальные планы обучения.

Промежуточный интервал обучения. Данная программа перепроверяет те знания, которые вы возможно уже забыли. Суть его заключается в том, что ИИ отслеживает что и когда вы изучили. Благодаря этому оно способно выяснить ту информацию, что скорее всего вы могли забыть и рекомендовать повторить ее.

Обратная связь для учителей. На протяжении многих лет учителя оценивали друг друга, однако сейчас это делается уже не с помощью бумажных носителей, а все чаще используются чат бот с ИИ. Они способны собирать мнения через диалоговый интерфейс, как настоящий интервьюер. Кроме того, данная программа умеет выяснять причины того или иного мнения.

Виртуальные помощники. На данный момент уже существуют помощники для преподавателей, которые способны отвечать точно и быстро на запросы студентов, благодаря встроенным в них компьютерам с ИИ.

Чат Кампус. Данный проект способен помогать студентам, только что пришедшим в кампус освоиться. Чат Кампус всегда с радостью объяснит, как попасть в нужный кабинет, расскажет, как и куда подавать нужные документы. 
Персонализированное обучение. Персонализированное обучение относится к разнообразным образовательным программам, в которых темп обучения и учебный подход оптимизированы для потребностей каждого учащегося. Опыт учитывает предпочтения в обучении и конкретные интересы разных учащихся. Искусственный интеллект без проблем подберет нужный темп для обучающегося, чтобы тот мог лучше усвоить программу.

Адаптивное обучение. Оно предполагает, что ИИ способен отслеживать прогресс каждого ученика и либо корректировать курс, либо информировать учителя о материале, который конкретному ученику трудно понять.

Proctoring. Дистанционное обучение обычно предполагает проведение дистанционных экзаменов. Однако необходимо проследить, чтобы студент написал данный ему экзамен самостоятельно. Для этого на помощь приходят системы защиты на базе ИИ. Proctoring или Proctored Test - это механизм, обеспечивающий подлинность тестируемого и предотвращающий его / ее обман через проктора, который присутствует во время теста.

Накопление данных и персонализация. Уже сейчас ИИ способен предлагать ближайшие кафе по интересам в зависимости от геолокации человека. Та же технология может быть применена, когда мы обучаемся, основанная на примерах только из той сферы, которая нас интересует.

Прогресс в области ИИ и машинного обучения впечатляет, но это далеко не предел возможностей. Существует огромное количество хороших идей, которые ИИ может реализовать. В целом, ИИ может значительно улучшить системы образования за счет его способности оптимизировать многие части работы учителя и автоматизировать другие части, в конечном итоге давая им все больше и больше времени, чтобы тратить его на своих учеников.

\section{Список литературы}

1. Зарипова Р.С. Особенности и тенденции развития современного инженерного образования / Р.С. Зарипова, О.А. Пырнова // Совре- 
менные исследования социальных проблем. Красноярск: НаучноИнновационный Центр, 2018. Т.9. №8-2. С. 43-46.

2. Зарипова Р.С. Глобальные тренды современного образования // NovaUm.Ru. 2018. № 13. C. 232-234.

3. Зарипова Р.С. Современные тенденции информатизации образования / Р.С. Зарипова, С.П. Миронов // NovaUm.Ru. 2018. №12. С. 18-19.

\section{References}

1. Zaripova R.S. Osobennosti i tendentsii razvitiya sovremennogo inzhenernogo obrazovaniya / R.S. Zaripova, O.A. Pyrnova // Sovremennye issledovaniya sotsial'nykh problem. Krasnoyarsk: Nauchno-Innovatsionnyy Tsentr, 2018. T.9. №8-2. S. 43-46.

2. Zaripova R.S. Global'nye trendy sovremennogo obrazovaniya // NovaUm. Ru. 2018. № 13. S. 232-234.

3. Zaripova R.S. Sovremennye tendentsii informatizatsii obrazovaniya / R.S. Zaripova, S.P. Mironov // NovaUm.Ru. 2018. №12. S. 18-19. 